\title{
PENAFSIRAN SAHABAT DALAM TAFSIR ATH-TABARI (ANALISIS AYAT BASMALAH)
}

\author{
Salehuddin Mattawang \\ Universitas Islam Negeri Alauddin Makassar \\ E-mail: mattawangsalehuddin@gmail.com
}

\begin{tabular}{|c|c|c|}
\hline Received & Revised & Accepted \\
\hline 4 July 2021 & 2 Agustus 2021 & 20 September 2021 \\
\hline
\end{tabular}

\section{INTERPRETATION OF SAHABAT IN THE TAFSIR ATH-TABARI (ANALYSIS OF AYAT BASMALAH)}

\begin{abstract}
This study aims to analyze the Sahabat interpretation of the basmalah reading in Surah al-Fatihah in the book of Tafsir al-Tabari. The research purpose is the biography of ath-Tabari, and how is the sahabat interpretation of the basmalah reading in the book of ath-Tabari's commentary. The reseach was qualitative approach in the form of library research with the primary data source is the book of tafsìr Jami' al-Bayān fî Ta'wìl al-Qur'ān kitab tafsir ath-Thabari. The results of this study indicate that there are at least two meanings of basmalah from the Sahabat interpretation in the ath-Tabari commentary book, namely first, as an ethic in praying where by reading the basmalah wasilah, Allah will always give blessings in all activities, secondly, as a shield to avoid oneself from all harm.
\end{abstract}

Keywords: interpretation, Sahabat, Basmalah, and Ath-Thabari.

\begin{abstract}
Abstrak
Penelitian ini bertujuan untuk menganalisa penafsiran sahabat tentang bacaan basmalah pada surah al-fatihah dalam kitab tafsir ath-Thabari. Rumusan masalahnya ada dua yaitu bagaimana biografi ath-Thabari?, dan bagaiamana penafsiran sahabat tentang bacaan basmalah pada kitab tafsir athThabari? Jenis penelitian ini adalah penelitian kepustakaan (library research) dengan sumber data primernya adalah tafsir Jami' al-Bayān fí Ta'wïl al-Qur'ān kitab tafsir ath-Thabari yang berjudul. Hasil penelitian ini menunjukkan bahwa setidaknya ada dua makna basmalah dari penafsiran sahabat pada kitab tafsir ath-Thabari yaitu pertama, sebagai etika dalam berdoa dimana dengan wasilah bacaan basmalah itu, maka Allah akan senantiasa memberikan keberkahan dalam sagala aktivitas, kedua, sebagai tameng untuk menghindarkan diri dari segala marabahaya.
\end{abstract}

Kata kunci: tafsir, sahabat, basmalah, dan Ath-Thabari.

\section{Pendahuluan}

Allah menciptakan makhluk yang bernama manusia sebagai makhluk yang terbaik ditengah-tengah banyaknya makhluk tuhan yang lain. Disamping manusia di sematkan sebagai makhluk terbaik, tetapi manusia juga dapat jatuh menjadi makhluk yang lebih 
rendah, lebih hina dari makhluk yang terendah, kecuali manusia senantiasa beriman dan melakukan perbuatan-perbuatan yang baik.

Dipahami bahwa al-Qur'an menjadi petunjuk untuk segenap umat manusia, jika ingin selamat maka pahamilah isi al-Qur'an. Akan tetapi, untuk memahami petunjuk Allah dalam al-Qur'an sulit menangkap maknanya jika tanpa adanya penafsiran. Dan salah satu dari sekian kitab tafsir diantaranya adalah kitab tafsir Jami' al-Bayān fí Ta'wìl al-Qur'ān karya Ibnu Jarir ath-Thabari.

Pada pembahasan ini, pemakalah fokus terkait tentang basmalah yang terdapat pada surah al-fatihah. Mengingat bahwa basmalah seringkali digunakan dalam membuka atau melakukan segala aktivitas baik dalam ibadah maupun terkait muamalah. Rasulullah SAW. bersabada:

Artinya:

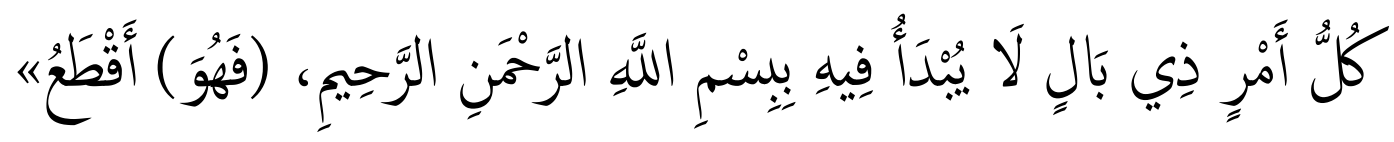

Setiap perkara yang tidak dimulai didalamnya bismillāhirahmānirahïm maka tertolak. ${ }^{1}$ Dikutip dari Kompas.com yang dirilis oleh Fobes bahwa daftar orang terkaya didunia adalah Elon Musk seorang nonmuslim pengusaha perusahaan mobil listrik otomatis Tesla dan Perusahaan roket luar angkasa SpaceX, berusia 50 tahun dengan total kekayaan ditaksir 220,9 miliyar dollar AS atau sekitar 3.102 triliun. ${ }^{2}$ Meski tidak mengenal apa itu basmalah dan apalagi mengucapkan basmalah namun ia tetap menjadi kaya raya bergelimpangan harta. Disatu sisi, ada umat Islam yang senantiasa mengucapkan basmalah, memohon kepada Allah berupa kekayaan harta, jabatan, dan kesehatan namun ternyata berujung dengan kekecewaan. Nah, melalui ini mungkinkah Allah melakukan diskriminasi kepada umatnya ? ataukah dimana letak rahmān dan rahïm-Nya ?

Olehnya itu, menarik jika melihat pandangan Ibnu Jarir ath-Thabari terkait basmalah dalam kitab tafsir beliau, dimana bahkan syekh manna al-Qattan saja pernah berkomentar bahwa kitab tafsir beliau adalah yang paling mulia dan agung, karena kitab beliau menjadi rujukan utama oleh para mufassir. ${ }^{3}$

\section{Metode Penelitian}

Penelitian ini menggunakan penelitian kualitatif yang berbentuk library research (penelitian Pustaka). Dalam hal jenis penelitiannya menggunakan penelitian deskriptif verifikatif. Penelitian ini dilaksanakan untuk menelusuri dan menganalisa penafsiran sahabat Nabi saw. terkait bacaan basmalah dalam kitab tafsir ath-Thabari kemudian membandingkan dengan pendapat para mufassir dalam kitab tafsir lainnya terkait bacaan basmalah, kemudian setelah itu barulah menarik kesimpulan dari penafsiran tersebut.

\footnotetext{
${ }^{1}$ Syamsuddin, Abu al-'Aun Muhammad bin Ahmad bin Sālim al-Safaraini al-HambaГi, Lawāmi' alanwari al-Bahiyati wa sawāti' al-asrāri al-aśariyati lisyarhi al-durrati al-madiyati fì 'aqdi firqati mardiyah, Juz I, ( Damaskus: Muassasah al-Khāfiqaini wa maktabatuha, 1402H/1982M), h. 38

${ }^{2}$ Jawahir Gustav, Daftar 5 Orang terkaya di Dunia 2021, Elon Musk geser Jeff Bezos, https:/www.kompas.com/tren/read/2021/10/20/140000465/daftar-5-orang-terkaya-di-dunia-2021-elonmusk-geser-jeff-bezos?page=all. , (24 November 2021.)

${ }^{3}$ Manna Khalil al-Qattān, Mabāhis Fï Ulümil Qur'ān terj. Mudzakir, Studi Ilmu-ilmu al-Qur'an, h. 573.
} 


\section{Hasil dan Pembahasan \\ Biografi Ath-Thabari}

Ath-thabari memiliki nama lengkap yaitu Muhammad bin Jarir bin Yazid bin katsir bin Ghalib, Abu Ja'far. Beliau dilahirkan di kota Amul (kota terbesar di Tabarsan). Mayoritas ahli sejarah memaparkan bahwa beliau dilahirkan pada tahun $224 \mathrm{H}$, namun adapula mengatakan tahun $225 \mathrm{H}^{4}$ dan wafat tahun $310 \mathrm{H}^{5}$ di baghdad. dipaparkan bahwa beliau adalah seorang ulama yang diakui baik dari segi keilmuan, amal dan segi kedalaman pengetahuan mengenai al-Qur'an dan jalan-jalan riwayat baik yang sahih maupun yang daif serta keadaan-keadaan sahabat dan tabiin. ${ }^{6}$

Begitu banyak yang menjadi buku hasil karya Ibn jarir selain kitab tafsir Jami' alBayān fí Ta'wìl al-Qur'ān, juga ada kitab lain seperti kitab Tarikhul Umam wal Mulūk wa Akhbäruhum, Al-Adāb al-Hamïdah wal Akhlak an-Nafïsah, dan beberapa kitab lain. Dikatakan beliau aktif menulis selama 40 tahun dengan perkiraan setiap harinya menulis 40 lembar. Jika demikian, selama 40 tahun diprediksi tulisan beliau sebanyak 1.768.000 lembar. Bahkan Ibn Jarir mengatakan bila jumlah kertas yang pernah ditulis dibagi usianya sejak masih baligh sampai wafatnya, maka setiap hari beliau menulis 14 lembar.

Syaikh Abdul Fattah dalam bukunya memaparkan bahwa ath-Thabari pernah bertanya kepada teman-temannya, " apakah kalian semangat untuk menulis al-Qur'an?" "berapa tebal bukunya?" baliknya bertanya." Tiga puluh ribu lembar," jawab Thabari." Wah, itu hanya menghabis-habiskan umur saja, tidak mungkin terampung!" maka beliaupun meringksanya dalam 3000 lembar saja dengan 30 jilid besar, dimana beliau mendiktekannya mulai tahun $283 \mathrm{H}$ sampai $290 \mathrm{H}$ sekitar 7 tahun lamannya ${ }^{8}$

Dalam penulisan beliau, selain menggunakan system isnad juga menggunakan metode tahlili. Dimana beliau menyoroti ayat-ayat al-Quran dengan memaparkan segala makna dan aspek yang terkandung didalamnya sesuai dengan urutan bacaan yang terdapat dalam al-Qur'an mushaf. ${ }^{9}$

\section{Penafsiran Sahabat terkait Basmalah dalam Tafsir Jami' al-Bayān fi Ta'wìl al-Qur'ān karya} Ath-Thabari

Terjemahnya:

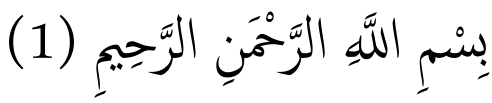

Dengan menyebut nama Allah yang maha pengasih lagi maha penyayang. ${ }^{10}$

Melalui jalur Abdullah bin Abbas biasa dikenal Ibnu Abbas salah salah satu sahabat Rasulullah saw. Beliau lahir tiga tahun sebelum Rasulullah hijrah, dan disaat Rasulullah saw. wafat beliau masih sangat belia yaitu berusia sekitar 13 tahun. ${ }^{11}$

\footnotetext{
${ }^{4}$ Abu Ja'far Muhammad bin Jarìr ath-Thabari, Jami' al-Bayān fí Ta'wìl al-Qur'ān, Jilid 3 (Bairut Dār al-Fiqr), h. 3

${ }^{5}$ Muhammad Yusuf, dkk, Studi Kitab Tafsir: Menyuarakan teks yang Bisu, (Yogyakarta:TERAS, 2004), h. 20-21.

${ }^{6}$ Manna Khalil al-Qattān, Mabāhis Fì Ulümil Qur'ān terj. Mudzakir, Studi Ilmu-ilmu al-Qur'an,

(Cet. IV, Jakarta: Ummul Qura, 2019), h. 572-573.

${ }^{7}$ Mustafa Ash-Shawi, Manhaj fi at-Tafsir Mansya'ah al-Ma'arif, (Iskandariyah, t.t), h. 304.

${ }^{8}$ Syaikh Abdul Fattah, Qimatuz Zaman 'Indal 'Ulamā, terj. Abu Umar Basyir dkk. Manajemen Waktu Para Ulama, (Cet.I, Solo: Zamzam, 2012), h. 78.

${ }^{9}$ M. Quraish Shihab dkk, Sejarah dan Ulüm al-Qur'an (Jakarta: Pustaka Firdaus, 2008), h. 172.

${ }^{10}$ Muhammad bin Jarī bin Yazìd bin Kașir bin Ghalib, Abu Ja'far Ath-Thabari, Jāmi' al-Bayān fí Ta’wil al-Qur'ān, Juz 1 .( Beirut: Muassasah al-Risālah: 1420 H/2000 M), h. 115.
} 


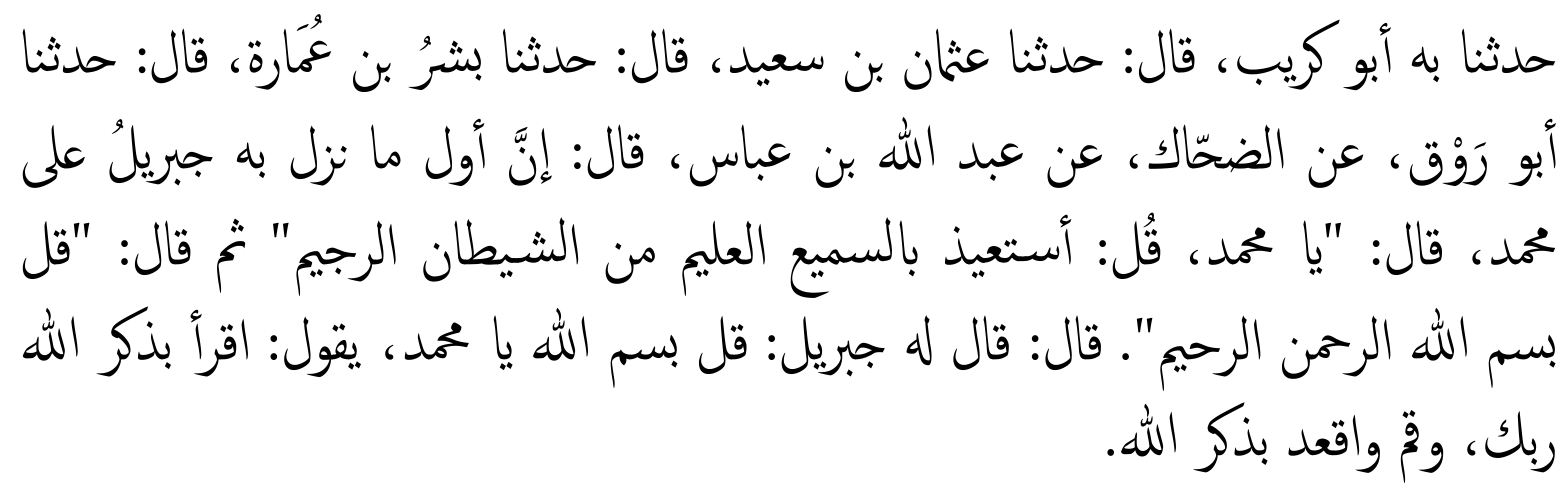

Dalam hal penafsiran sahabat terkait basmalah, melalui jalur Abu Karib menceritakan kepada kami, katanya Ustman bin Sa'id menceritakan kepada kami, katanya Basyar bin Imarah menceritakan kepada kami dari Adh-Dhahak dari Abdullah bin Abbas, ia berkata bahwa ," yang pertama turun dari Jibril kepada Nabi Muhammad adalah beliau berkata 'wahai Muhammad, ucapkanlah 'aku berlindung dari syetan yang terkutuk', kemudian berkata lagi, ucapkanlah 'dengan menyebut nama Allah yang maha pengasih lagi maha penyayang', ia berkata, Jibril berkata kepadanya ucapkanlah, bimillahi wahai Muhammad, ia berkata, 'Bacalah dengan dzikir (menyebut) Allah, Tuhanmu, bangun dan duduklah dengan berdzikir kepada Allah. ${ }^{12}$

Melalui pemaparan ini ath-thabari dalam tafsirnya berkata bahwa: jika ada yang mengatakan bahwa, apabila penakwilan bimillăh seperti yang dikatakan, lalu bagaimana kalimat bismillāh dapat berarti "aku membaca dengan nama Allah", "aku berdiri dengan nama Allah", atau “ aku duduk dengan nama Allah?” padahal diketahui bahwa setiap orang yang membaca al-Qur'an, berdiri ataupun duduk semuanya hanya dengan taufiq dan pertolongan dari Allah semata. Dan alangkah tepatnya menurut beliau diucapkan billahirahmānirrahïm dan bukan bismillahirahmani rahim karena orang yang mengatakan, "aku membaca dengan nama Allah yang maha pengasih lagi maha penyayang" atau "aku berdiri dengan Allah" yang maknanya lebih jelas daripada mengatakan "aku membaca dengan nama Allah" atau "aku berdiri dengan nama Allah", karena perkataan ini menyiratkan makna kerancuan pada pendengarnya, yaitu dengan selain Allah? Jadi sebenarnya makna yang dimaksud adalah bukan seperti yang dipahami. Tetapi kata bismillăh artinya "aku memulai sesuatu dengan menyebut nama Allah" atau "aku membaca dengan menyebut nama Allah", atau "aku berdiri dengan menyebut nama Allah dan mengingat -Nya", bukan artinya, 'aku membaca dengan Allah' atau 'aku berdiri dengan Allah.'

Maka muncul pertanyaan kembali, kalau memang demikian lalu mengapa dikatakan bismillah, sementara diketahui bahwa kata ism'(nama) tidak sama fungsinya dengan tasmiyah (penyebutan nama)? Maka jawabannya adalah: karena orang Arab seringkali memilih bentuk kata sifat tidak seperti bentuk kata kerjanya. Seperti perkataan orang akrimtu fulānan karämatan aku menghormati fulan dengan sebuah penghormatan. Dengan melalui pemaparan ath-thabari maka benarlah kata bismillāh artinya aku memulai

\footnotetext{
${ }^{11}$ Hepi Andi bastoni, Kisah Sahabat Nabi: Abdullah bin Abbas, Muda Usianya Luas Ilmunya, https://Www.republika.co.id/berita/1113wV/kisah-sahabat-nabi-abdullah-bin-abbas-muda-usianya-luasilmunya. (23/12/2021).

${ }^{12}$ Muhammad bin Jarì bin Yazìd bin Kașīr bin Ghalib, Abu Ja'far Ath-Thabari, Jāmi' al-Bayān fí Ta’wìl al-Qur'ān, Juz 1, h. 115.
} 
pekerjaan dengan menyebut nama Allah. Dan ini sesuai dengan pendapat Abdullah bin Abbas ra. sahabat Rasulullah saw. ${ }^{13}$

Kembali melalui jalur Abu Karib menceritakan kepada kami, katanya Ustman bin Sa'id menceritakan kepada kami, katanya Basyar bin Imarah menceritakan kepada kami, katanya Abu Rauq menceritakan kepada kami dari Adh-Dhahakk dari Abdullah bin Abbas, ia berkata "Yang pertama kali turun dari Jibril kepada Muhammad adalah perkataannya"Wahai Muhammad ucapkanlah asta'ízu bissamil'alim minasyaitānirajīm (aku berlindung kepada dzat yang maha mendengar lagi maha mengetahui godaan syetan yang terkutuk. Kemudian berkata, katakanlah: Bimillahirrahmani Rahim yang artinya: Dengan menyebut nama Allah yang maha pengasih lagi maha penyayang. ${ }^{14}$

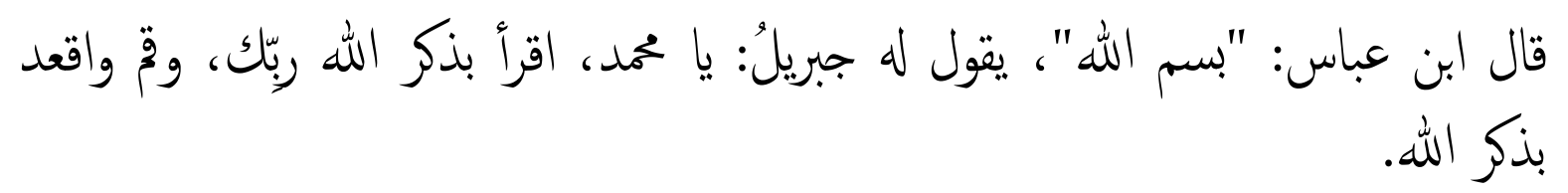

Ibnu Abbas berkata bismillah maksudnya: Jibril berkata kepada beliau, "wahai Muammad bacalah dengan menyebut nama Allah, Tuhanmu, bangkitlah dan duduklah dengan menyebut nama-Nya.

Ath-thabari dalam tafsirnya membenarkan penakwilan Ibnu Abbas bahwa orang yang mengucapkan bismillähirahamāni rahïm ketika hendak membaca, dalam artian: " aku hendak membaca dengan menyebut nama Allah dan mengingat-Nya", bukan seperti yang dipahami oleh sebagian orang bahwa artinya "aku membaca dengan Allah." Karena kita manusia diperintahkan untuk sekiranya memulai setiap pekerjaan dengan mengucapkan nama Allah, bukan dengan menyebut akan sifat dan keagungan Allah. Dimana kita manusia diperintahkan untuk senantiasa menyebut nama-Nya ketika hendak akan menyembelih binatang, ketika makan, minum, menulis dan melakukan segala aktifitas termasuk membaca kita suci al-Qur'an. ${ }^{15}$

Hal ini, sesuai dengan pamaparan M. Qurais Shihab tatkala membahas terkait basmalah bahwa: jika hanya diterjemahkan kedalam bahasa Indonesia Bimillähirahmanirrahim dengan nama Allah yang maha pengasih lagi maha penyayang itu belum jelas, maka bagi beliau hal itu butuh sisipan, ketika menyembelih hewan dengan membaca bismillah maka berarti dengan nama Allah saya memulai menyembelih, dengan nama Allah saya mulai membaca, saya mulai makan. Maka ketika itu pula akan terpenuhi rahmat Allah dan kasih sayang Allah, dan ketika membaca basmalah dalam memulai aktifitas itu berarti sebagai bentuk penghambaan diri manusia bahwa kita tak akan mungkin akan melaksanakan segala aktifitas tanpa ada kuasa Allah swt. Dalam artian menanamkan dalam hati sanubari dari satu sisi kelemahan kita tapi dalam saat yang sama ditanamkan di dalam hati bahwa Allah maha kuasa, apa yang Dia mau beri tidak dapat ditahan oleh orang lain, dan apa yang Dia akan tahan tidak akan dapat diberi oleh orang lain. $^{16}$

\footnotetext{
${ }^{13}$ Muhammad bin Jarī bin Yazìid bin Kașīr bin Ghalib, Abu Ja'far Ath-Thabari, Jāmi’ al-Bayān fí Ta'wil al-Qur'ān, Juz 1, h. 116-117.

${ }^{14}$ Muhammad bin Jarī bin Yazìd bin Kașir bin Ghalib, Abu Ja'far Ath-Thabari, Jāmi' al-Bayān fí Ta'will al-Qur'ān, Juz 1, h.117.

${ }^{15}$ Muhammad bin Jarīr bin Yazīd bin Kașir bin Ghalib, Abu Ja'far Ath-Thabari, Jāmi' al-Bayān fí Ta'wïl al-Qur'ān, Juz 1, h. 117-118.

16“Basmalah" (Ceramah), Najwa Shihab, (24 November 2021.)
} 
Dijelaskan pula melalui jalur Abu said khudri sahabat Rasulullah, yang nama lengkap beliau adalah Abu Sa'ad bin Malik bin Sinan bin Tsa'labah bin Ubaid bin al-Abjar (Khudrah) bin Auf bin haris bin al-Khazraj al -Anshari al-Khazraji. ${ }^{17}$ yang secara lengkapnya Ismail bin Fadhl menceritakan kepada kami, katanya Ibrahim bin 'Ala bin Adh-Dhahak mencertakan kepada kami, katanya, Ismail bin Ayyasy menceritakan kepada kami dari Ismail bin Yahya, dari Ibnu Abi Mulaikah dari orang yang menceritakan kepadanya, dari Ibnu Mas'ud dan Mas'ar bin Kidam dari Athiyah dari Abu Sa'id, ia berkata bahwa Rasulullah SAW bersabda,

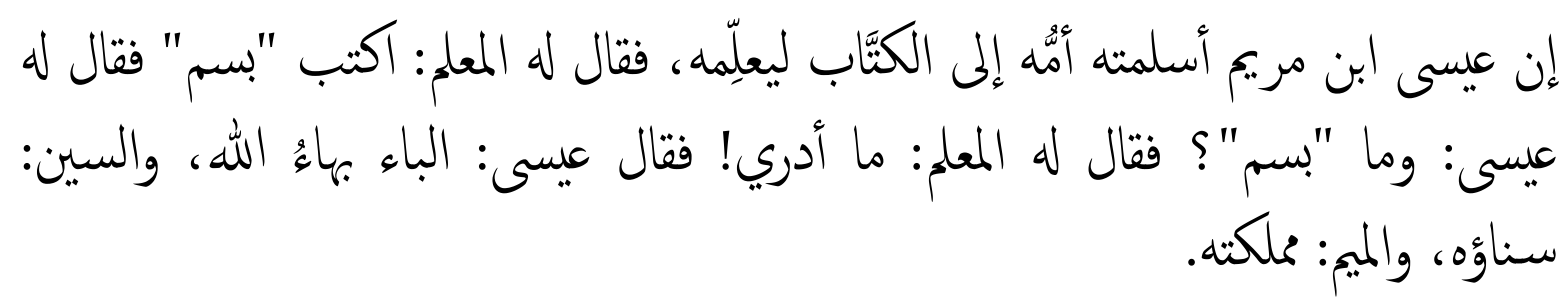

Sesungguhnya Isa bin Maryam diserakan oleh Ibunya kepada seoarang guru agar mengajarinya, lalu sang guru berkata kepadanya, tulislah bismi, Isa bertanya, dan apakah bismi itu? Sang guru menjawab, tidak tahu! Lalu Isa mengatakan, Adapun huruf ba artinya bahāullah (keindahan Allah), Huruf Sin artinya sanāuhu (keagungan-Nya), dan huruf mīm artinya mamlūkatuhü (kerajaan-Nya). ${ }^{18}$

Ditemukan pula yang semakna dengan hadis diatas pada kitab tafsir Ibnu Katsir. ${ }^{19}$ Namun Ath-Thabari mengomentari hal ini, menurut beliau dalam tafsinya terdapat kekhawatiran akan kesalahan perawinya, karena yang dimaksud dengan $b \bar{a} \overline{s i n}$ dan $\overline{m i m}$ sebenarnya adalah proses belajar anak kecil yang baru mengenal huruf hijaiyyah $a, b a, j a$ $d a$, namun, dipahami salah dan ditakwilkan dengan bismi. Dan menurut ath-thabari hal ini jelas tidak sesuai jika kalimat bismillāhirrahmanirahïm dibaca oleh seorang qari' terhadap ayat-ayat al-qur' an, dimana maknanya sangat jauh dari pemahaman orang-orang Arab.

Melalui ini, Abdullah bin Abbas menakwilkan kata Allah adalah yang dituhankan oleh segala sesuatu dan disembah oleh seluruh makhluk. ${ }^{20}$ Allah adalah diantara namanama Allah yang berjumlah 99 atau lebih, dan kata Allah adalah yang paling banyak disebutkan didalam al-Qur' an yaitu sebanyak 2696 kali. Dalam artian bahwa tiada yang patut disembah, dipuji, ditaati selain hanya Ia, tiada yang benar-benar kuasa selain hanya Ia, tiada yang benar-benar tinggi selain hanya Ia dan seterusnya. ${ }^{21}$

Sedangkan arrahmānirahïm yang maha pengasih lagi maha penyayang, ath-thabari menjelaskan bahwa adalah dua nama yang diambil dari akar kata arrahmah (kasih sayang), lalu mengapa terjadi pengulangan lafal sementara maknanya sama? Ath-thabari menambahkan bahwa ia tidak seperti yang diduga, akan tetapi masing-masing dari keduanya memiliki makna yang tersendiri. Secara etimologi, tidak seorangpun ahli bahasa

${ }^{17}$ Arya Saputra Abu Said al-Khudri, Mujahid dan Mufti Madinah. https://markazsunnah.com/abusaid-al-khudri-mujahid-dan-mufti-madinah/. (23/12/2021).

${ }^{18}$ Muhammad bin Jarī bin Yazìid bin Kașìr bin Ghalib, Abu Ja'far Ath-Thabari, Jāmi' al-Bayān fí Ta'wïl al-Qur'ān, Juz 1, h. 120-121.

${ }^{19} \mathrm{Abu}$ al-Fidā Ismaì bin 'Umar bin Kàsìr al-Qarsyi al-Busra al-Dimasqiy, Tafsìr al-Qur'ān al'Azīm, Juz 1 (Damaskus: Dār Tayyibah Linnasyar wattawzih, 1420 H/ 1999 M), h. 119.

${ }^{20}$ Muhammad bin Jarīr bin Yazìd bin Kașì bin Ghalib, Abu Ja'far Ath-Thabari, Jāmi' al-Bayān fī Ta'wil al-Qur'ān, Juz 1, h. 121.

${ }^{21}$ Bey Arifin, Samudra Alfatihah, (Cet.IV, Surabaya: PT Bina Ilmu, 1976), h. 61. 
yang memungiri bahwa kata arrahmān memiliki makna yang lebih spesifik daripada kata arrahim meskipun keduanya berasal dari akar kata yang sama. Kemudian dari akar katanya memiliki makna yang lebih spesifik daripada bentuk kata benda aslinya, dimana yang disifati dengannya lebih utama daripada yang disifati dengan kata benda aslinya jika menyangkut pujian ataupun celaan. ${ }^{22}$

Bey Arifin menambahkan bahwa arrahmān dan arrahïm adalah 2 nama Allah yang paling banyak termaktub di dalam al-Qur'an sesudah Allah dan masing-masing disebut sekitar 800 kali dalam al-Qur'an. Ar-Rahmān mengandung arti yang Allah berikan rahmat kepada seluruh makhluk-Nya dengan tidak pilih kasih, dengan tidak memperbedakan antara makhluk yang berakal atau tidak, antara makhluk-Nya manusia yang baik ataupun yang jahat, yang beriman ataupun yang kafir. Tetapi rahmat yang diberikan itu adalah merupakan rahmat-rahmat yang kecil, yang rendah merupakan hidup, susunan tubuh, makan-minum, istri anak turunan, Kesehatan dan kekayaan dan lain-lain lagi. Yaitu bermacam-macam rahmat yang hanya selama hidup di dunia ini saja. Sedangkan ar-Rahim berarti yang Allah berikan rahmat-rahmat besar, rahmat yang tak dapat dinilai dengan seluruh harta dan kekayaan, rahmat yang kekal dan abadi. Rahmat yang bukan merupakan hidup, susunan tubuh, makan-minum, kesehatan, kekayaan dan lainnya, tetapi rahmatrahmat agung yang merupakan jalan lurus hidup (sirạtal muștaqīm), perasaan bahagia yang sumbernya iman, perasaan cinta terhadap Allah, Rasul-rasul dan ajaran-ajaran-Nya, akhirnya rahmat terbesar yang menjadi induk segala rahmat adalah surga jannatun na'im, dan lain-lain rahmat besar yang abadi dalam kehidupan akhirat. ${ }^{23}$

Melalui pemaparan diatas terkait lafal bismillähirahmanirrahïm setidaknya memiliki makna:

\section{Etika dalam berdoa}

Dipahami bahwa, berdoa artinya kita memohon atau meminta. Bukan bermohon atau meminta kepada manusia, tapi memohon atau meminta kepada Allah sang penciptasang pengabul permohonan. Dalam berdoa juga memiliki cara-cara yang baik atau etika dalam berdoa, agar permohonan atau permintaan kita di ijabah oleh Allah swt. Sebagai si pemohon maka semestinyalah merendahkan diri dengan serendah-rendahnya, dan meninggikan/memuliakan Allah dengan setinggi-tingginya dan semulia-mulianya. Dan dengan mengucapkan basmalah adalah bentuk kerendahan diri kita kepada Allah dan memuliakan/meninggikan Allah dengan semulia-mulianya/setinggi-tingginya. ${ }^{24}$

M. Quraish Shihab mengatakan bahwa basmalah ketika di pecah-pecah menjadi huruf maka terdiri dari 19 huruf, kata Ibnu Mas'ūd: Siapa yang ingin agar dihindarkan Allah dari Zabaniyah yang 19 maka hendaklah ia membaca bismillāhirahmaniRahïm maka Allah menjadikan setiap hurufnya sebagai tameng dari masing-masing mereka. M. Quraish menambahkan bahwa Zabaniayah yang 19 adalah Malaikat yang ditugaskan Allah malaksanakan tugas penyiksaan terhadap orang-orang yang masuk kedalam neraka. ${ }^{25}$ Olehnya itu, dengan memulai suatu aktivitas ketika berdoa membaca bismilllähirahmānirrahïm maka keberkahan Allah akan senantiasa menghinggapi, meskipun hal itu hanya hal sepele/kecil. Karena ketika melibatkan Allah maka hal yang

\footnotetext{
${ }^{22}$ Muhammad bin Jarīr bin Yazìd bin Kașir bin Ghalib, Abu Ja'far Ath-Thabari, Jāmi' al-Bayān fí Ta'wil al-Qur'ān, Juz 1, h. 123.

${ }^{23}$ Bey Arifin, Samudra Alfatihah, h. 61-62.

${ }^{24}$ Bey Arifin, Samudra Alfatihah, h. 58-59.

25“Basmalah" (Ceramah), Najwa Shihab, 24 November 2021.
} 
dianggap kecil tak diperhitungkan akan menjadi besar, luar biasa dan penuh dengan keberkahan karena memulai berdoa dengan membaca bismillāhirrahmānirrahïm.

2. Menghindarkan dari segala marabahaya

Hidup didunia selain Allah swt memberikan berupa kesenangan ataupun kegembiraan, juga Allah menyajikan kepada hambanya berupa berbagai marabahya. Sebagai mahkluk sosial yang berakal, Allah memberikan alternatif untuk mendapatkan berbagai kesenangan, dan sebisa mungkin menghidarkan diri dari berbagai bahaya. Begitu banyak kecelakaan yang terjadi, begitu pula yang terjangkit penyakit bukan hanya anak kecil yang belum cukup akalnya tapi juga orang dewasa dan bahkan orang tua.

Pada intinya kecelakaan, penyakit marabahaya tidak mengenal siapa dia? berapa usianya? sudah siapkah dia menerima bahaya? Dari sinilah Agama dengan perantaraan Rasulullah saw. mengajarkan bahwa untuk menghindarkan dari berbagai bahaya tidak cukup dengan akal, kemampuan, ilmu pengetahuan dan kewaspadaan saja, tetapi harus di barengi pula ketika mengawali segala aktivitas dengan mengucapkan bismillāhirāhmanirrahïm, agar senantiasa mendapatkan pertolongan dari Allah swt. karena hanya Allah sajalah yang tahu setiap marabahaya yang datang. ${ }^{26}$

\section{Simpulan}

1. Ath-thabari memiliki nama lengkap yaitu Muhammad bin Jarir bin Yazid bin katsir bin Ghalib, Abu Ja'far. Beliau dilahirkan di kota Amul (kota terbesar di Tabarsan). Mayoritas ahli sejarah memaparkan bahwa beliau dilahirkan pada tahun $224 \mathrm{H}$, namun adapula mengatakan tahun $225 \mathrm{H}^{27}$ dan wafat tahun $310 \mathrm{H}^{28}$ di baghdad. dipaparkan bahwa beliau adalah seorang ulama yang diakui baik dari segi keilmuan, amal dan segi kedalaman pengetahuan mengenai al-Qur'an dan jalan-jalan riwayat baik yang sahih maupun yang daif serta keadaan-keadaan sahabat dan tabiin.

2. Terkait ayat basmalah didalam al-Qur'an dari penafsiran sahabat dalam kitab tafsir ath-Thabari maka setidaknya memiliki dua makna yaitu pertama, sebagai etika dalam berdoa dimana melalui inilah Allah akan senantiasa memberikan keberkahan dalam segala aktivitas, dan yang kedua menghindarkan diri dari segala marabahaya karena yang berkehendak atas segala sesuatu adalah Allah sang maha kuasa, olehnya awalilah segala aktivitas dengan senantiasa mengucapkan bismillähirrahmänirrahïm agar senantiasa mendapatkan pertolongan dari Allah swt.

${ }^{26}$ Bey Arifin, Samudra Alfatihah, h. 82-83.

${ }^{27} \mathrm{Abu}$ Ja'far Muhammad bin Jarìr ath-Thabari, Jami' al-Bayān fī Ta'wìl al-Qur'ān, Jilid 3 (Bairut Dār al-Fiqr), h. 3

${ }^{28}$ Muhammad Yusuf, dkk, Studi Kitab Tafsir : Menyuarakan teks yang Bisu, (Yogyakarta:TERAS, 2004), h. 20-21. 


\section{DAFTAR PUSTAKA}

Abdu, Syaikh al-Fattah, Qimatuz Zaman 'Indal 'Ulamā, terj. Abu Umar Basyir dkk. Manajemen Waktu Para Ulama, (Cet.I, Solo: Zamzam, 2012).

Abu, Syamsuddin, al-'Aun Muhammad bin Ahmad bin Sālim al-Safaraini al-Hambali, Lawāmi’ al-anwari al-Bahiyati wa sawāti' al-asrāri al-aśariyati lisyarhi al-durrati almadiyati fï 'aqdi firqati mardiyah, Juz I, ( Damaskus: Muassasah al-Khāfiqaini wa maktabatuha, 1402H/1982M).

Al-Fìda Abu Ismail bin 'Umar bin Kasir al-Qarsyi al-Busra al-Dimasqiy, Tafsir alQur'ān al-'Azīm, Juz 1 (Damaskus: Dār Tayyibah Linnasyar wattawzih, 1420 H/ $1999 \mathrm{M})$.

Andi, Hepi bastoni, Kisah Sahabat Nabi: Abdullah bin Abbas, Muda Usianya Luas Ilmunya, https://WwW.republika.co.id/berita/1113WV/kisah-sahabat-nabi-abdullahbin-abbas-muda-usianya-luas-ilmunya. (23/12/2021).

Arifin, Bey, Samudra Alfatihah, (Cet.IV, Surabaya: PT Bina Ilmu, 1976).

Ash-Shawi, Mustafa, Manhaj fi at-Tafsir Mansya'ah al-Ma'arif, (Iskandariyah, t.t).

"Basmalah" (Ceramah), Najwa Shihab, (24 November 2021.)

Gustav, Jawahir, Daftar 5 Orang terkaya di Dunia 2021, Elon Musk geser Jeff Bezos, https://www.kompas.com/tren/read/2021/10/20/140000465/daftar-5-orangterkaya-di-dunia-2021-elon-musk-geser-jeff-bezos?page=all. , (24 November 2021.)

Ja'far, Abu Muhammad bin Jarìr ath-Thabari, Jami' al-Bayān fī Ta'wìl al-Qur'ān, Jilid 3 (Bairut Dār al-Fiqr).

Jarī, Muhammad bin bin Yazìd bin Kașīr bin Ghalib, Abu Ja'far Ath-Thabari, Jämi' alBayān fì Ta'wīl al-Qur'ān, Juz 1 .( Beirut: Muassasah al-Risālah: 1420 H/2000 M).

Khalil, Manna al-Qattān, Mabāhis Fì Ulümil Qur'ān terj. Mudzakir, Studi Ilmu-ilmu alQur'an, (Cet. IV, Jakarta: Ummul Qura, 2019).

Quraish, M. Shihab dkk, Sejarah dan Ulum al-Qur'an (Jakarta: Pustaka Firdaus, 2008).

Saputra, Arya ,Abu Said al-Khudri, Mujahid dan Mufti Madinah.

https://markazsunnah.com/abu-said-al-khudri-mujahid-dan-mufti-madinah/. $(23 / 12 / 2021)$.

Yusuf, Muhammad dkk, Studi Kitab Tafsir : Menyuarakan teks yang Bisu, (Yogyakarta:TERAS, 2004). 